\title{
FRACTAL NATURE OF POROSITY IN VOLCANIC TIGHT RESERVOIRS OF THE SANTANGHU BASIN AND ITS RELATIONSHIP TO PORE FORMATION PROCESSES
}

\author{
WEIMING WANG, ${ }^{*, \dagger,}$ ZHIXUAN WANG,${ }^{*}$ XUAN CHEN, ${ }^{\ddagger}$ FEI LONG,$\ddagger$ \\ SHUANGFANG LU, ${ }^{*} \|$ GUOHONG LIU, ${ }^{\S}$ WEICHAO TIAN ${ }^{*}, \dagger$ and YUE SU* \\ ${ }^{*}$ Research Institute of Unconventional Oil $\mathscr{G}$ Gas and \\ Renewable Energy, China University of \\ Petroleum (East China), Qingdao, Shandong 266580, P. R. China \\ ${ }^{\dagger}$ Shandong Provincial Key Laboratory of \\ Depositional Mineralization 85 Sedimentary Mineral \\ Shandong University of Science and \\ Technology, Qingdao, Shandong 266590, P. R. China \\ $\ddagger$ Petroleum Exploration and Development Research \\ Institute, Petrol China Tuha Oilfield Company \\ Hami, Xinjiang 839009, P. R. China \\ $\S_{\text {No. } 6} 6$ Oil Production Plant, Petrol China Daqing Oilfield Company \\ Daqing, Heilongjiang 163114, P. R. China \\ wangweiming6686@163.com \\ "lushuangfang@qq.com
}

Received December 6, 2017

Accepted January 8, 2018

Published February 27, 2018

\begin{abstract}
In this paper, in a case study of Santanghu Basin in China, the morphological characteristics and size distribution of nanoscale pores in the volcanic rocks of the Haerjiawu Formation were investigated using the results of low temperature nitrogen adsorption experiments. This
\end{abstract}

\footnotetext{
"Corresponding author.

This is an Open Access article published by World Scientific Publishing Company. It is distributed under the terms of the Creative Commons Attribution 4.0 (CC-BY) License. Further distribution of this work is permitted, provided the original work is properly cited.
} 
W. Wang et al.

research showed that within the target layer, a large number of nanoscale, eroded pores showed an "ink bottle" morphology with narrow pore mouths and wide bodies. The fractal dimension of pores increases gradually with increasing depth. Moreover, as fractal dimension increases, BET-specific surface area gradually increases, average pore diameter decreases and total pore volume gradually increases. The deeper burial of the Haerjiawu volcanic rocks in the Santanghu Basin leads to more intense erosion by organic acids derived from the basin's source rocks. Furthermore, the internal surface roughness of these corrosion pores results in poor connectivity. As stated above, the corrosion process is directly related to the organic acids generated by the source rock of the interbedded volcanic rocks. The deeper the reservoir, the more the organic acids being released from the source rock. However, due to the fact that the Haerjiawu volcanic rocks are tight reservoirs and have complicated pore-throat systems, while organic acids dissolve unstable minerals such as feldspars which improve the effective reservoir space; the dissolution of feldspars results in the formation of new minerals, which cannot be expelled from the tight reservoirs. They are instead precipitated in the fine pore throats, thereby reducing pore connectivity, while enhancing reservoir micro-preservation conditions.

Keywords: Fractal Dimension; Pore Morphology; Pore Size Distribution; Pore Formation; Santanghu Basin.

\section{INTRODUCTION}

Tight oil is the latest in a series of strategic breakthroughs after shale gas, and one of the major sources of future global oil reserve growth, following the successful exploration and development of tight oil in North America.110 At present, North America is the only region in the world where commercial exploitation of tight oil is widespread. The output of tight oil in the United States (US) has soared since 2006, by 2012, the production of tight oil accounted for $29 \%$ of the total output of US oil and gas, which successfully reversed the situation in the US of a production decline lasting 24 years.1112 According to the BP World Economic Prospects Outlook for BP2030, released in January 2013, global oil output is projected to grow by 16.1 million (barrels/day) by 2030, with nearly half of these barrels coming from tight oil ${ }^{13}$ China has also carried out a far-reaching "tight oil revolution" after the "shale gas revolution" drawing on the successful exploration experiences of US tight oil. Currently, China has found tight oil in the Triassic, the Permian in the Junggar Basin, the Cretaceous in the Songliao Basin, Paleogene strata of the Bohai Bay Basin, and has the required resource base for large-scale exploration. 14115 Although domestic and foreign scholars have accumulated considerable experience in geological exploration in tight oil reservoirs, the research on tight oil has thus far mostly concentrated on reservoirs such as tight sandstones, shales or carbonate rocks. Few scholars have included volcanic tight oil reservoirs as the focus of their research!16!17
The Santanghu Basin, situated in the northeast of Xinjiang, China, is rich in volcanic reservoir resources! $\frac{18}{18}$ particular, the volcanic tight reservoirs of the Haerjiawu Formation have become key areas in the growth of Turpan-Hami oilfield reserves. From a petroleum exploration perspective, the Haerjiawu volcanic reservoirs are distinct from volcanic reservoirs in other petroliferous basins for the following two reasons: (1) the volcanic reservoirs in other basins are gas-dominated, while the Haerjiawu volcanic reservoirs in the Santanghu Basin are oil-dominated; (2) The volcanic reservoirs in other basins are mostly thick, massive units, while the volcanic reservoirs of Haerjiawu Formation in the Santanghu Basin are mainly thinly bedded units in close proximity to a sequence of carbonaceous mudstones. Since the Haerjiawu volcanic rocks are a newly discovered exploration play in the Santanghu Basin, previous researchers have mainly focused on reservoir formation conditions and the main controlling factors of volcanic reservoirs. The studies of the micro-porosity structure of these volcanic tight reservoirs, especially quantitative studies of nanoscale pores have not been undertaken in the volcanic tight reservoirs of the Santanghu Basin.

Fractal dimension is a significant parameter in the quantitative evaluation of microscopic pore structure. It not only describes pore heterogeneity qualitatively, but also characterizes pore roughness quantitatively ${ }^{1920}$ Fractal theory has been widely implemented in the field of petroleum exploration and development, especially in the study of reservoir micro-pore structure. It has developed into a 
simple and effective way to quantitatively characterize the heterogeneity and complexity of pore structure in low permeability reservoirs. Fractal dimension values typically range between 2 and 3 . Its physical meaning is defined as the comparison of the local and regional similarity of pore structures in the reservoir, as well as the intensity of the pore size distribution. Geologically, it permits the comprehensive characterization of the complexity of the reservoir's pore structure. The numerical value of this fraction can be used as an important index when describing the pore structure of the reservoir. As the value of the general fractal dimension approaches 3 , reservoir pore-throat surfaces become less smooth, grain sorting becomes poorer, pore size distribution becomes more complicated and overall the reservoir can be described as more heterogeneous; the opposite case applies as the value of this fraction approaches 2 , and the reservoirs can be considered as more homogenous. It can be shown that the fractal dimension is an ideal parameter that can comprehensively describe the self-similarity of a suite of features of micro-pores in reservoir rocks, which in turn reflects the micro-heterogeneity of the pore structure of the reservoir. This provides an effective method of quantitative characterization of pore size distribution, pore structure heterogeneity and reservoir complexity. The application of fractal dimension in unconventional hydrocarbon geology is based on the results of different experiments such as constant pressure mercury intrusion, high pressure mercury intrusion and nuclear magnetic resonance. 21.25 However, the focus of this study is to understand the nanoscale pore development of the Haerjiawu volcanic rocks in the Santanghu Basin. In this paper, pore fractal characteristics of volcanic tight reservoirs are studied based on low temperature nitrogen adsorption experiments, and the geological origin and significance of microscopic pores are analyzed by Field Emission Scanning Electron Misroscopy (FESEM).

\section{SAMPLES AND EXPERIMENTS}

\subsection{Geological Background and Sample Collection}

The Santanghu Basin is located in the Barkol Kazak Autonomous County and Yiwu County in the northeast of Xinjiang. Its interbedded lithologies trend NW-SE, sandwiched between the Mochenwula and Suhaitu hills (Fig. (1). The basin is about $500 \mathrm{~km}$ long and $40-70 \mathrm{~km}$ wide with an area of $2.3104 \mathrm{~km}^{2}$. It borders the Junggar Basin to the west, Turpan-Hami Basin to the south and Mongolia to the northeast. The Santanghu Basin is characterized by north-south zoning and east-west

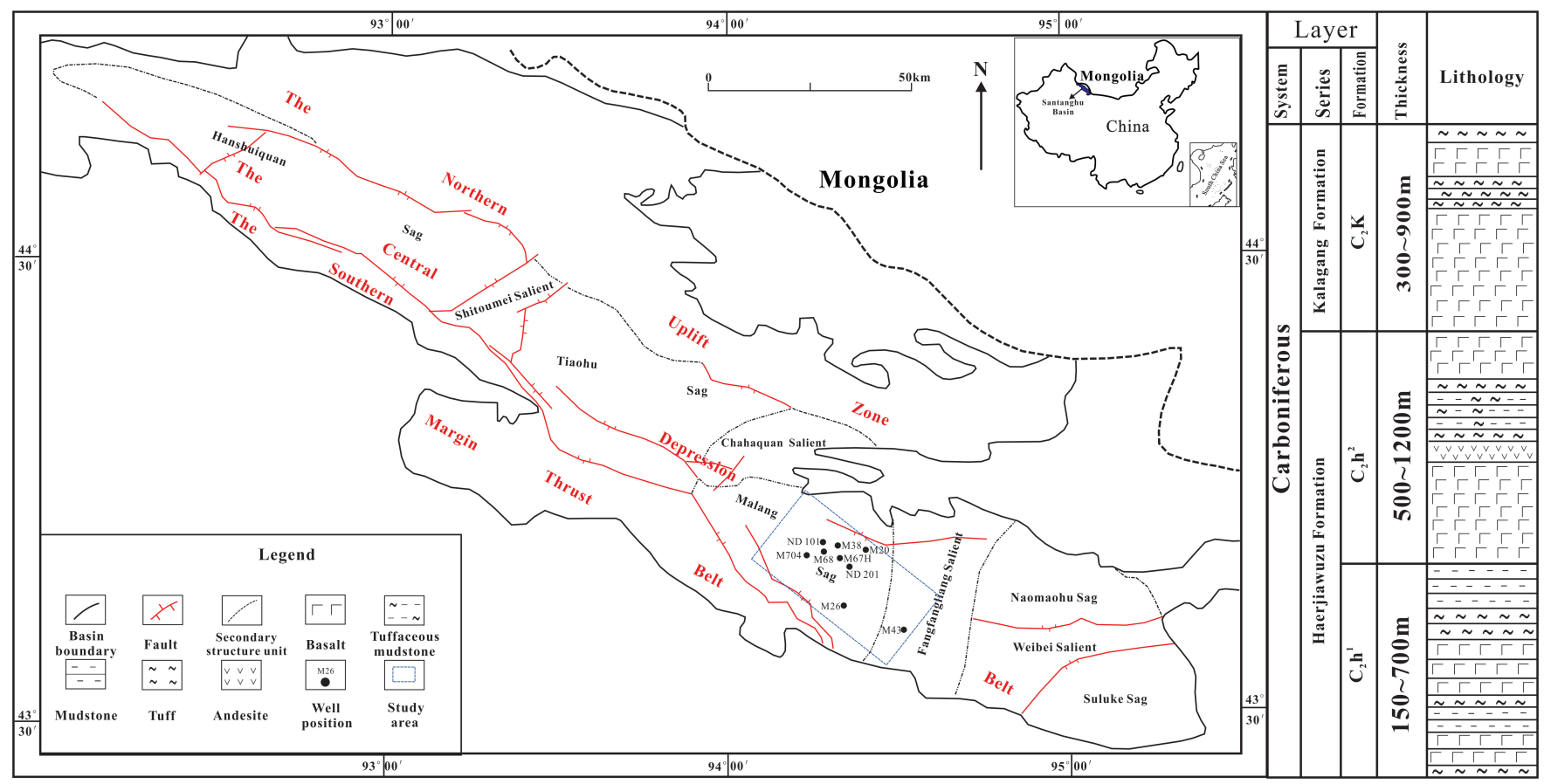

Fig. 1 Santanghu Basin study area location. 
striking fault block structures. The fundamental tectonic units consist of the northern thrust uplift belt, the central depression belt and the southern thrust nappe belt.26 The Malan sag is a key exploration area within the Santanghu Basin and is located in the southern part of the Central Depression Belt. There is a large nose structure belt from east to west which develops within the sag. The volcanic rocks in the study area are mainly distributed (from top to bottom) in the Kalagang Formation $\left(\mathrm{C}_{2} \mathrm{~K}\right)$ and the Haerjiawu Formation. The Haerjiawu Formation consists of pyroclastic sedimentary rocks, pyroclastic rocks and volcanic lava interbedded with carbonaceous mudstones, tuffaceous mudstones and marls. During the deposition of the Carbonaceous mudstones in the Haerjiawu Formation, the areal extents of lacustrine sedimentation are considerable and the source rocks are widely distributed. The volcanic rocks adjacent to these carbonaceous mudstones are the most interesting in terms of reservoir development. In summary, the key target of the research in this paper is the dense volcanic rock in the Haerjiawu Formation.

In this study, 15 volcanic rocks were collected from around the volcanic rocks of Haerjiawu Formation in Santanghu Basin target area, and studies using approaches such as low temperature nitrogen adsorption and FESEM. The sample depth interval ranged from $1320 \mathrm{~m}$ to $3812 \mathrm{~m}$, and the samples were collected from nine wells. The lithology of the sampled volcanic rocks is gray-brown basalt. The rocks have complex textures and show development of vesicular and amygdaloidal structures.

\subsection{Experiment Analysis}

\subsubsection{Low temperature nitrogen adsorption experiment}

The low temperature nitrogen adsorption experiments were performed using the Surfer-type surface area and pore size distribution analyzer produced by Thermo Fisher. The Surfer analyzer uses static volumetric gas adsorption technology to determine the micro-structural parameters of solids and powders under controlled temperature and pressure conditions. The pore size distribution range of the instrument is $1.5-200 \mathrm{~nm}$, and the minimum specific surface area is $0.0005 \mathrm{~m}^{2} / \mathrm{g}$. In the experiment, pure nitrogen with a purity of more than 99.999\% was used as adsorbate, and the pressure was increased to the saturated vapor pressure $P_{0}$ of nitrogen $\left(P_{0}\right.$ is about $\left.0.101 \mathrm{MPa}\right)$ at a temperature of $77 \mathrm{~K}$. The pressure was then gradually reduced to determine the amount of nitrogen adsorbed by the sample at different relative pressures $P / P_{0}$. The ratio of system pressure to saturated vapor pressure of nitrogen $P / P_{0}$ was plotted as abscissa and the adsorption capacity per sample mass $V$ as ordinate, and this enabled the nitrogen adsorptiondesorption isotherm to be plotted 2728

\subsubsection{Field emission scanning electron microscopy}

The instrument used to perform these experiments was the ZEISS SIGMA FESEM with ultrahigh-resolution scanning image viewing capability. Integrating the latest digital image processing technology, this device provides high resolution scanned images ${ }^{29}$ Based on the principle of secondary electron imaging; image observation and image processing are performed on the surface of various solid samples either coated or uncoated by film to obtain ultra-micro-structure information. The purpose of this experiment is mainly to observe and study the surface features of nanoscale samples. Firstly, the sample was polished by argon ions to obtain a smooth and fresh rock surface. In order to enhance the conductivity and improve the image quality, plating was then performed on the sample surface using an ion sputter with a thickness of about $10 \mathrm{~nm}$. After sample preparation, ZEEISS SIGMA FESEM can be used to carry out electron imaging of the surface of the sample. The imaging mode permits observation of the size, shape and distribution of pores, and therefore interprets pore type and genesis.

\section{RESULTS AND DISCUSSION}

\subsection{Pore Structure Characteristics of Volcanic Tight Reservoirs}

\subsubsection{Morphological characteristics of the pores}

The low temperature $\mathrm{N}_{2}$ adsorption-desorption curve can not only quantitatively characterize pore size, but also the morphological characteristics of nanoscale pores. 3133 The adsorption and desorption curves of the sampled volcanic rocks in the target layer show obvious hysteresis loops, indicating the development of nanoscale pores in the volcanic tight reservoirs of the Haerjiawu Formation in the Santanghu Basin, with strong heterogeneity. 


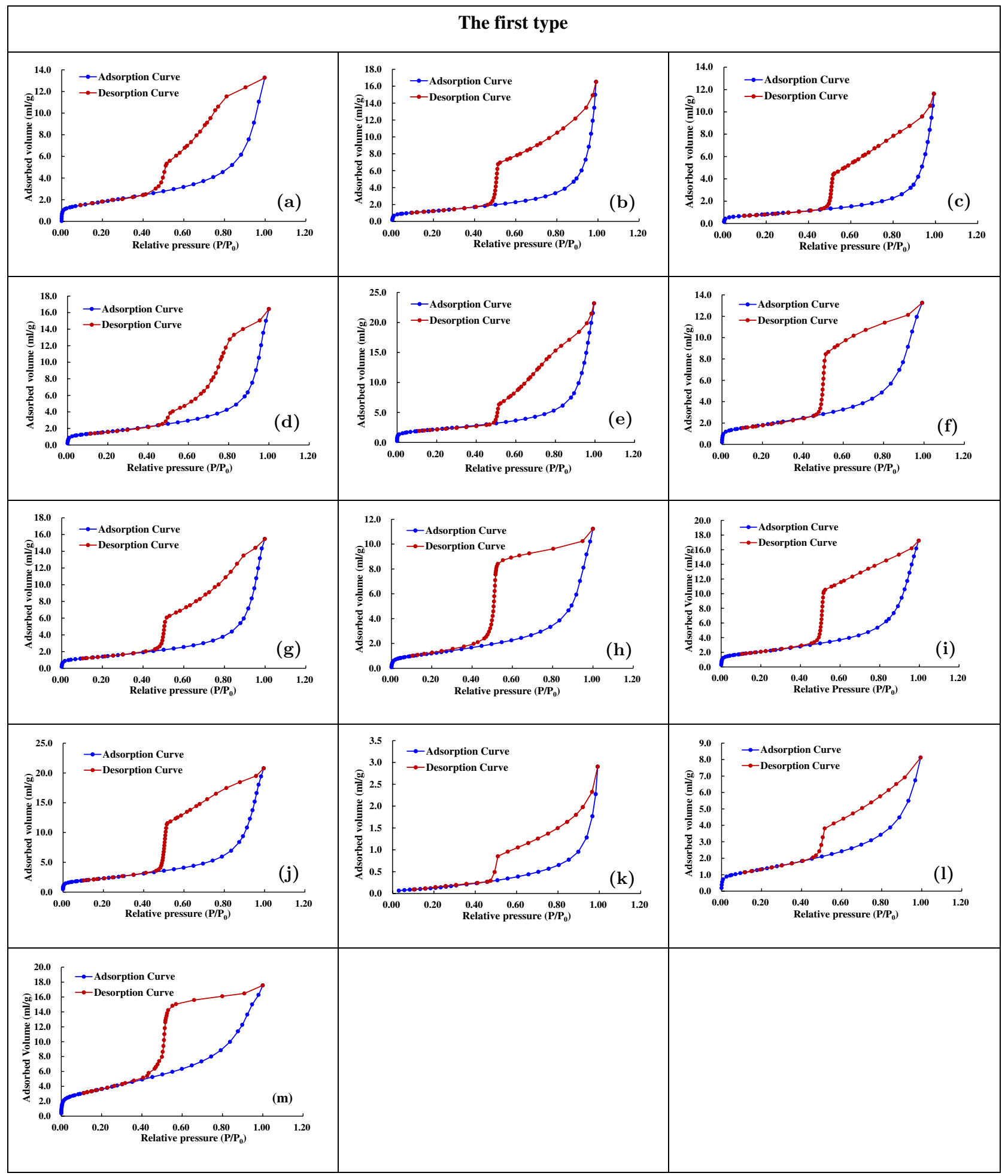

(a)

Fig. 2 Adsorption and desorption curves of the volcanic rocks of the Haerjiawu Formation, Santanghu Basin. (a) M43 well $1319.95 \mathrm{mC}_{2} \mathrm{~h}$ brown basalt; (b) M20 well $2141.875 \mathrm{mC}_{2} \mathrm{~h}$ gray basalt; (c) NY110 well $2599.525 \mathrm{mC}_{2} \mathrm{~h}$ dark gray fluorescent basalt; (d) M38 well $3037.525 \mathrm{mC}_{2} \mathrm{~h}$ gray oil-bearing volcanic breccia; (e) $\mathrm{M} 67$ well $3083.06 \mathrm{mC}_{2} \mathrm{~h}$ gray fluorescence basalt; (f) NY201 well $3143.985 \mathrm{mC}_{2} \mathrm{~h}$ gray oil basalt; (g) NY201 well $3151.345 \mathrm{mC}_{2} \mathrm{~h}$ dark gray fluorescent basalts; (h) NY201 well $3155.82 \mathrm{mC}_{2} \mathrm{~h}$ gray oil basalt; (i) NY201 well $3162.875 \mathrm{mC}_{2} \mathrm{~h}$ deep gray basalt; (j) NY201 well $3184.74 \mathrm{mC}_{2} \mathrm{~h}$ dark gray oily basalt; (k) NY201 well $3187.5 \mathrm{mC}_{2}$ h dark gray oily basal; (l) M704 well $3470.865 \mathrm{mC}_{2} \mathrm{~h}$ gray fluorescence basalts; (m) M68 well $3486.275 \mathrm{mC}_{2} \mathrm{~h}$ gray-green fluorescent basal; (n) M26 well $3811.945 \mathrm{mC}_{2} \mathrm{~h}$ gray-green fluorescent andesite; (o) M67 well $2695.97 \mathrm{mC}_{2} \mathrm{~h}$ brown oily basalt. 


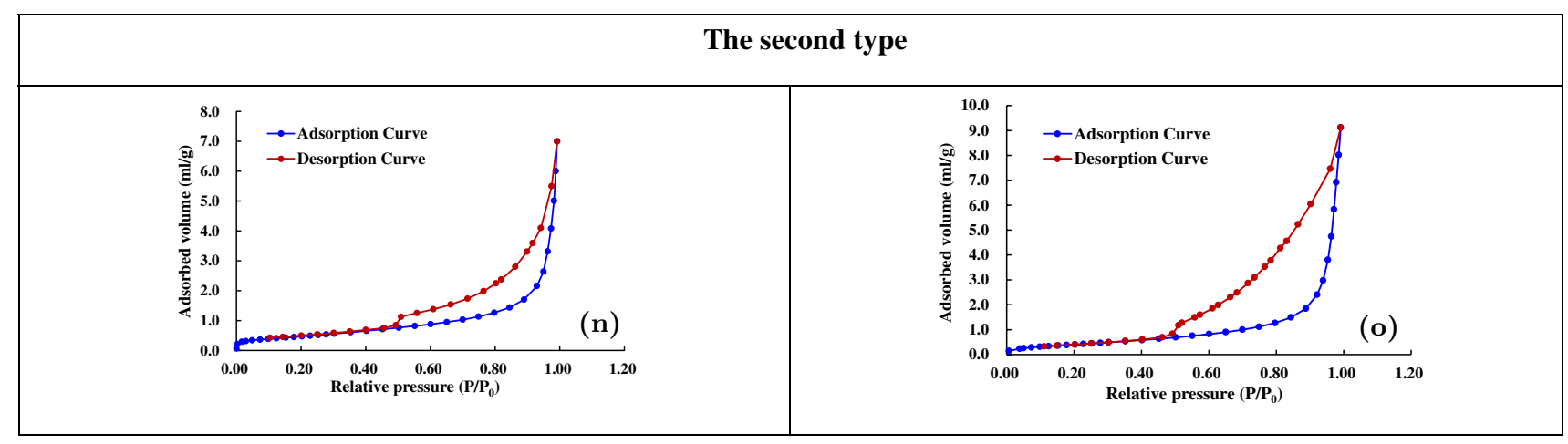

(b)

Fig. 2 (Continued)

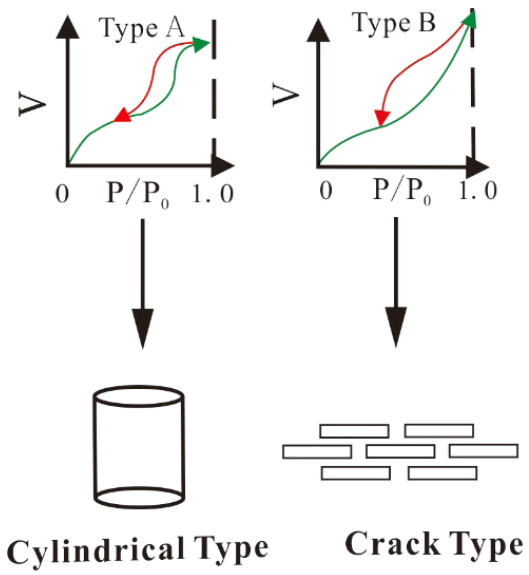

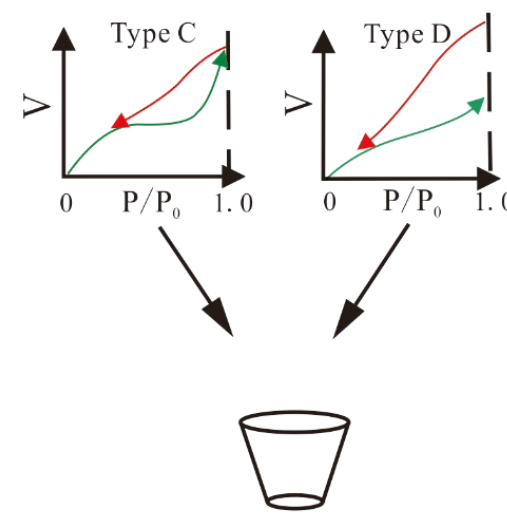

Conical Type

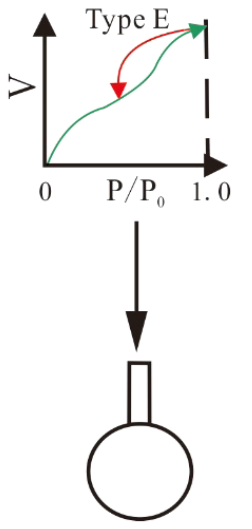

Ink Bottle Type

Fig. 3 Hysteresis loop classification and corresponding pore morphology of low temperature nitrogen adsorption. Source: Zhao Difei (2014).

The study of the adsorption-desorption curve enables the volcanic rocks in the target layer to be divided into two types: the adsorption and desorption curves of one set of samples are convex upward at low pressure $\left(0<P / P_{0}<0.05\right)$, signifying adsorption of liquid nitrogen on a monolayer of a rock sample surface, or microspore filling. With increasing relative pressure $\left(0.05<P / P_{0}<0.3\right)$, the adsorption isotherm is approximately linear, and liquid nitrogen undergoes multi-molecular layer adsorption. As the pressure continues to rise after the linear section, the isotherm continues to rise and assumes a downward concave shape, no further adsorption saturation occurs even when the equilibrium pressure approaches the saturated vapor pressure, indicating the condensation nitrogen in the capillary pores. When the relative pressure is high $\left(P / P_{0}>0.4\right)$, the adsorption and desorption curves of the samples no longer coincide, and the desorption curve drops sharply near the relative pressure of 0.5 , forming a hysteresis loop (Figs. 2a $2 \mathrm{~m}$ ).
The adsorption and desorption curves of the second set of samples were linear under the low pressure $\left(0<P / P_{0}<0.5\right)$. With increasing relative pressure $\left(P / P_{0}>0.5\right)$, the desorption curve and adsorption curve no longer coincide, and the change trend of the desorption curve is the same as that of the adsorption curve (Figs. 2h and 2b).

The morphological characteristics of hysteresis loops are widely used in the evaluation of unconventional reservoirs to deduce the morphology of microscopic pores in tight reservoirs. ${ }^{34}$ Pyun and Rhe ${ }^{35}$ argued that the formation of hysteresis loops is related to the pore structure of mesopores. Khalili et al. ${ }^{[36}$ and Budaeva and Zoltoev $\sqrt{37}$ argued that hysteresis loops at $P / P_{0}>0.5$ were associated with capillary condensation in the Ink Bottle-type. The relationship between hysteresis loop topography and pore morphology (Fig. [3] allows the division of pore morphology into four types: cylindrical, crack-shaped, conical, and ink bottle-shaped. From the analysis of the samples, 


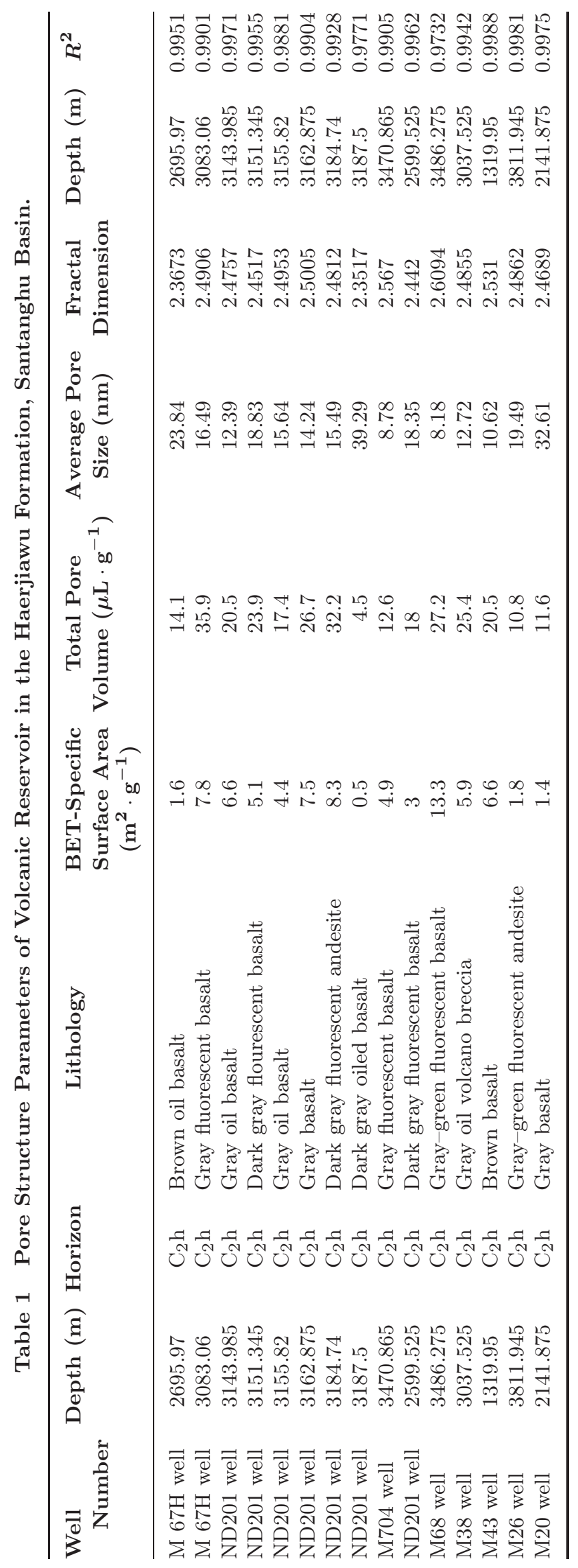


W. Wang et al.

the overall shape of the hysteresis curves associated with the first set of samples in Fig. 2 is more similar to type $\mathrm{E}$, and pore morphology is interpreted as an "ink bottle"-shaped hole with narrow mouth and wide body. The overall shape of the hysteresis curves of the second set of samples in Fig. 2 is closer to that of type $\mathrm{B}$, and the pore morphology is interpreted as having a "slit hole with parallel plate" structure. The "ink bottle"-shaped hole corresponds to the shape of pores formed by the water drop erosion. The "slit hole" pores arise from microcracking formed by tectonic stress, which agrees with the actual background stress field. The examination of the statistics of the 15 samples reveals that only two samples belong to the second pore morphology category (13\%), and 13 samples belong to the first category (87\%). Thus, we can say that the pore morphology of the Haerjiawu volcanic rocks in the Santanghu Basin is dominated by "ink bottle"shaped holes, accompanied by a small number of "slit holes" with parallel plate-shaped structures. Type C represents V-shaped hole, type D represents one or both ends of the open wedge $\mathrm{V}$-shaped hole. The pore morphology is similar, so type $\mathrm{C}$ and type $\mathrm{D}$ can be classified as conical-type. ${ }^{39}$

\subsubsection{Pore size distribution characteristics}

Liquid nitrogen adsorption experiments allow excellent characterization of the size of nanoscale

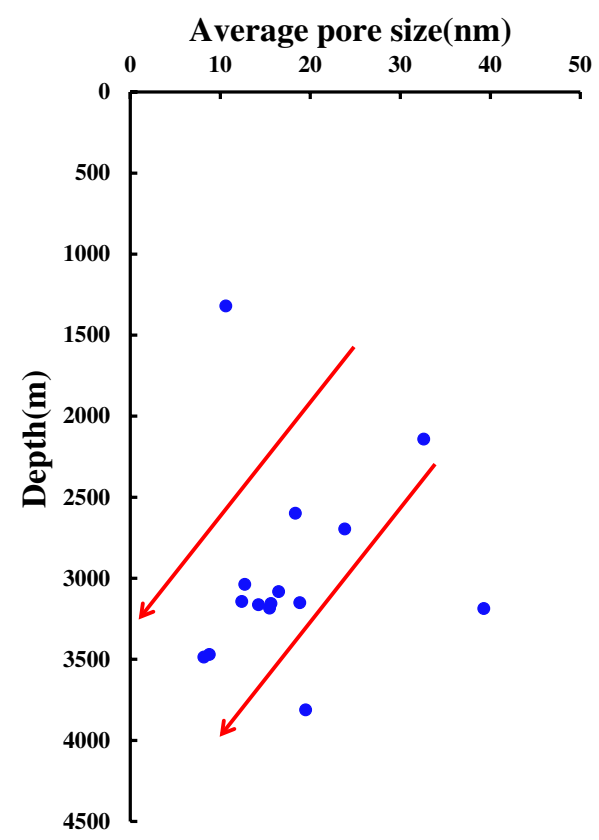

Fig. 4 The changing chart of average pore size and depth.

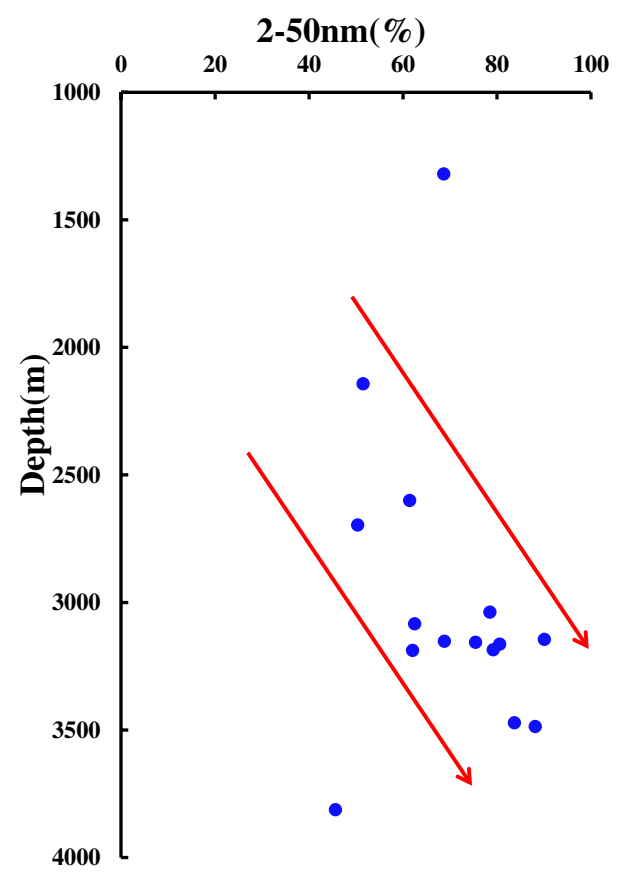

Fig. 5 The changing chart of mesopore 2-50 nm percentage.

pores. ${ }^{40}$ The pore structure parameters of the Haerjiawu Formation reservoir samples in the Santanghu Basin are shown in Table 1. It can be seen that the total pore volume of the samples is distributed in the range of 4.5 to $35.9 \mu \mathrm{L} \cdot \mathrm{g}^{-1}$ with an average of $20.1 \mu \mathrm{L} \cdot \mathrm{g}^{-1}$. The pore size distribution ranges from $8.18 \mathrm{~nm}$ to $39.29 \mathrm{~nm}$ with an average of $17.8 \mathrm{~nm}$. As can be seen from Fig. (4) average pore size decreases as depth increases. However, at the same time, the number of pores between $2 \mathrm{~nm}$ and $50 \mathrm{~nm}$ gradually increases (Fig. (5)). Thus, as the depth of the sample increases, the number of nanoscale pores increases, but they are relatively isolated and the average pore size decreases, due to poor interconnectivity.

\subsubsection{BET specific surface area and total pore volume}

In Table 1, the BET-specific surface area and total pore volume of different volcanic rock samples differ widely, with the BET-specific surface area ranging from $0.5 \mathrm{~m}^{2} / \mathrm{g}$ to $13.3 \mathrm{~m}^{2} / \mathrm{g}$ with a mean of $5.2 \mathrm{~m}^{2} / \mathrm{g}$; the total pore volume values are distributed between $4.5 \mu \mathrm{L} / \mathrm{g}$ and $32.2 \mu \mathrm{L} / \mathrm{g}$ with an average of $20.1 \mu \mathrm{L} / \mathrm{g}$. The specific surface area and the total pore volume show a significant positive correlation (Fig. 6): the larger the BET-specific surface area of the sample, the greater the total pore volume. 


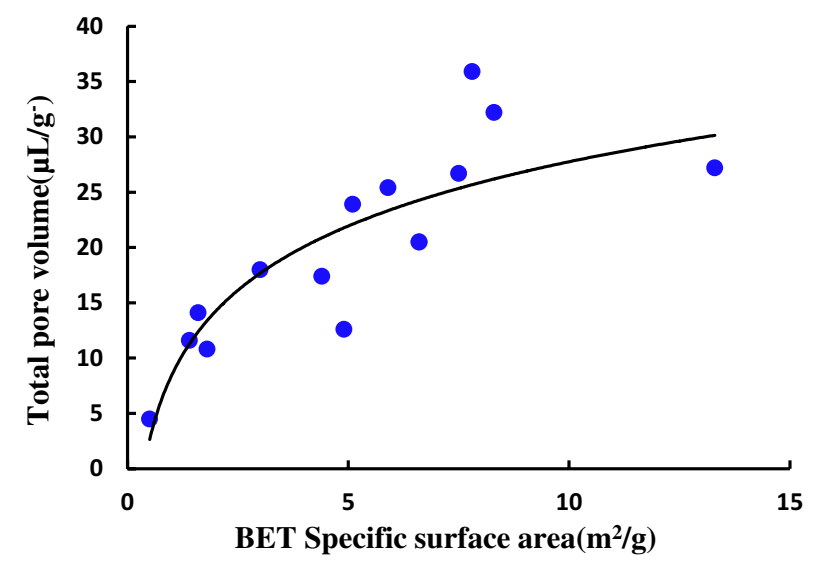

Fig. 6 Graph showing the changing relationship between BET-specific surface area and total pore volume.

\subsection{FHH Fractal Characteristics of Tight Volcanic Reservoirs}

\subsubsection{Fractal theory}

Fractal theory is a nonlinear mathematical theory founded in the mid-1970s. In the early 1980s, Mandelbrot, 14 a famous French mathematician, provided the definition of the term fractal, that is "a component whose composition resembles the whole in some way is called fractal", he went on to establish the new discipline of fractal geometry. Subsequently, people applied fractal theory to the study of pore structures in reservoir sandstones. Researchers found that the pore structure characteristics had a fractal nature and that the fractal dimension was the best description of this fractal nature, determined using molecular absorption methods and SEM. Many scholars have studied the fractal dimension and its application to the pore structure of reservoir sandstones, this has revealed that the fractal properties of the pore structures of reservoir sandstone are of great significance in the process of oil and gas accumulation, migration and recovery. For any geometry with a certain dimension, a certain value of $N$ can be obtained if it is measured with a "ruler" that is the same dimension, and infinite, if "ruler" is lower than its dimension, as well as 0 , if "ruler" is above its dimensions.

The mathematical expression describing this argument is shown as follows ${ }^{42}$ :

$$
N(r) \sim r^{-D_{H}} .
$$

Taking the natural logarithms of both sides of Eq, (11), the following result can be obtained:

$$
D_{H}=\ln N(r) / \ln \left(\frac{1}{r}\right),
$$

where $r$ is the feature length of the selected element, $N(r)$ is the number of features, $D_{H}$ is the Hausdorff dimension, which is called the fractal dimension here. Fractal geometry theory relating to fractal dimension of pore structure in porous media is a description of the complexity of its pore surface. The larger the fractal dimension, the more complex the pore surface. $\stackrel{43}{ }$

\subsection{2. $\quad$ FHH fractal model}

There are many methods of calculating the solid fractal dimension based on the gas adsorptiondesorption isotherms, including the particle size method, the fractal BET model, the FHH model and the thermodynamic method ${ }^{44}$ Among them, the FHH method, with its wide range of applicable scenarios and convenient calculation, is the most widely used. Avnir et al. $\frac{[4]}{}$ introduced the fractal dimension into the adsorption potential theory while researching gas molecule adsorption onto a porous solid with an uneven surface. This resulting in the FHH Eq. (3) describing the gas adsorption model of a fractal surface in the capillary condensation area $(>2 \mathrm{~nm})$ is

$$
\operatorname{Ln}(V)=(D-3) \operatorname{Ln}\left[\operatorname{Ln}\left(P_{0} / P\right)\right]+C .
$$

$P$ is the equilibrium pressure; $V$ is the adsorption volume corresponding to the equilibrium pressure $P ; K$ is a constant and refers to a linear relationship coefficient, the value of which is related to the adsorption mechanism; $C$ is a constant; $D$ is the fractal dimension, which lies between 2 and 3 . The larger the fractal dimension, the rougher the pore surface is, the more complex the pore structure will further affect the occurrence of fluid seepage. From Eq. (3), we can get the $\operatorname{Ln}\left[\operatorname{Ln}\left(P_{0} / P\right)\right]$ by $\operatorname{Ln}(V)$ by using the measured nitrogen adsorption isotherm, the fractal dimension of porous media can be obtained from the slope of the resulting line. As can be seen from Fig. 7 the porosity of the volcanic reservoirs in the study area shows significant fractal characteristics, and the correlation coefficients of the samples are all above 0.97 .

\subsubsection{Fractal dimension calculation}

The fractal dimension of the sample can be obtained from Eq. (3) (Table 1). The results show that the correlation coefficient of linear fitting is more than 0.97, which is good for fitting, indicating that the volcanic nanoscale pores have fractal characteristics. The fractal dimension $D$ of volcanics calculated 


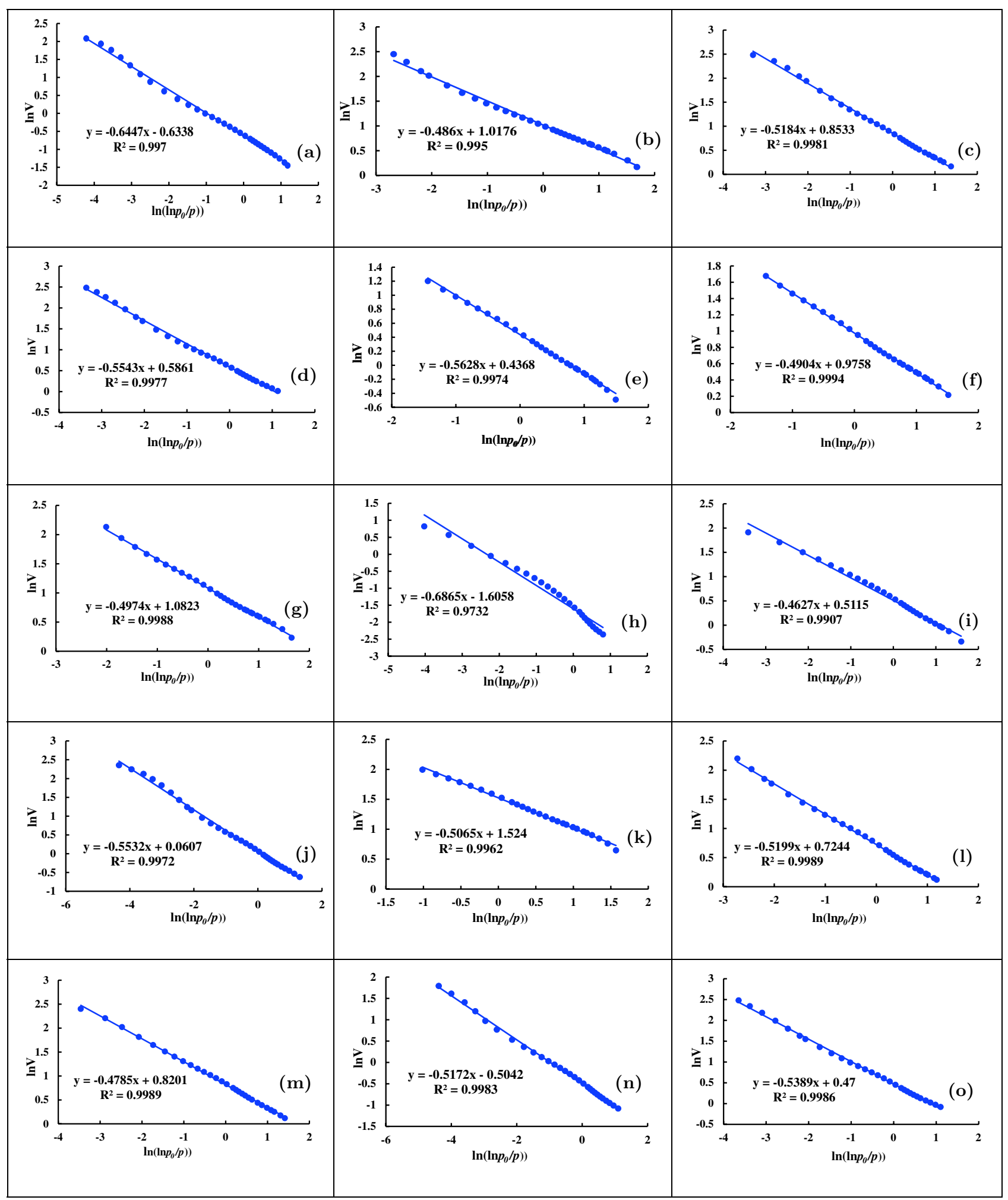

Fig. 7 Fractal fitting of volcanic rocks of the Haerjiawu Formation, Santanghu Basin. (a) M67 well $2695.97 \mathrm{mC} 2 \mathrm{~h}$ Brown oil basalt; (b) M67 well $3083.06 \mathrm{mC}_{2}$ h Gray fluorescent basalt; (c) ND201 well $3143.985 \mathrm{mC}_{2} \mathrm{~h}$ Gray oil basalt; (d) ND201 well $3151.345 \mathrm{mC}_{2} \mathrm{~h}$ Dark gray fluorescent basalt; (e) ND201 well $3155.82 \mathrm{mC}_{2} \mathrm{~h}$ Gray oil basalt; (f) $\mathrm{ND}_{201}$ well $3162.875 \mathrm{mC}_{2} \mathrm{~h}$ Dark gray basalt; (g) ND 201 well $3184.74 \mathrm{mC}_{2}$ h Dark gray oily basalt; (h) ND 201 well 3187.5 mC 2 h Dark gray oily basalt; (i) M704 well $3470.865 \mathrm{mC}_{2} \mathrm{~h}$ Gray fluorescent basalt; (j) ND201 well $2599.525 \mathrm{mC}_{2} \mathrm{~h}$ Dark gray fluorescent basalt; (k) M68 well $3486.275 \mathrm{mC}_{2} \mathrm{~h}$ Gray-green fluorescent basalt; (l) M38 well $3037.525 \mathrm{mC}_{2} \mathrm{~h}$ Gray oil-bearing volcanic breccia; (m) M43 well $1319.95 \mathrm{mC}_{2} \mathrm{~h}$ Brown basalt; (n) M26 well $3811.945 \mathrm{mC}_{2} \mathrm{~h}$ Gray-green fluorescent andesite; (o) M20 well $2141.875 \mathrm{mC}_{2} \mathrm{~h}$ Gray basalt. 
by $\mathrm{FHH}$ equation is between 2.35 and 2.61, indicating that the volcanic reservoir porosity is highly heterogeneous.

\subsection{Analysis of the Genesis of Pore Size in the Volcanic Reservoirs}

\subsubsection{Analysis of the relationship between the fractal dimension and pore morphology}

The fractal dimension calculated from Sec. 3.2 shows that the fractal dimension of the Haerjiawu volcanic rocks in the Santanghu Basin increases with the increasing depth (Fig. 8), indicating that inner pore surface roughness increases with depth. At the same time, there exists a good correlation among the fractal dimension and the BET-specific surface area, the average pore diameter and the total pore volume. With increasing fractal dimension, the BET area of the sample increases (Fig. 9). The smaller the average pore size (Fig. 10), the larger the total pore volume (Fig. 11). The above correlations demonstrate that the pores in the samples are increasing in size with increasing depth, but these are isolated pores (due to their small average pore size) with poor connectivity. The rough surfaces of the pores are interpreted as being related to selective dissolution of unstable minerals.

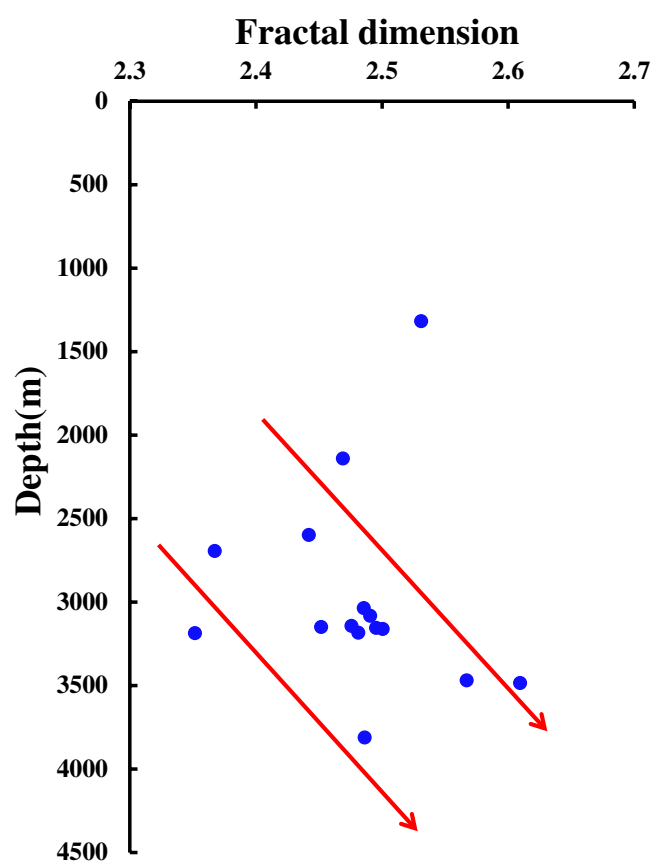

Fig. 8 The changing chart of fractal dimension and depth.

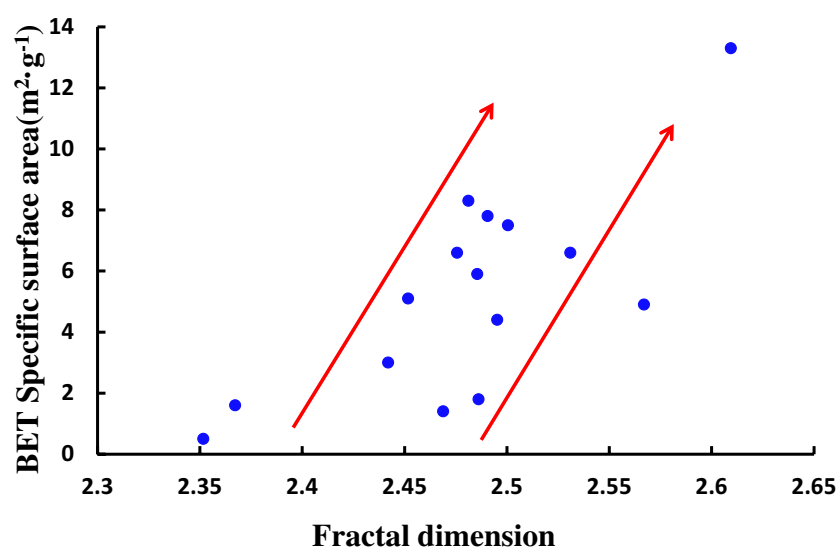

Fig. 9 The relations between fractal dimension and specific surface area.

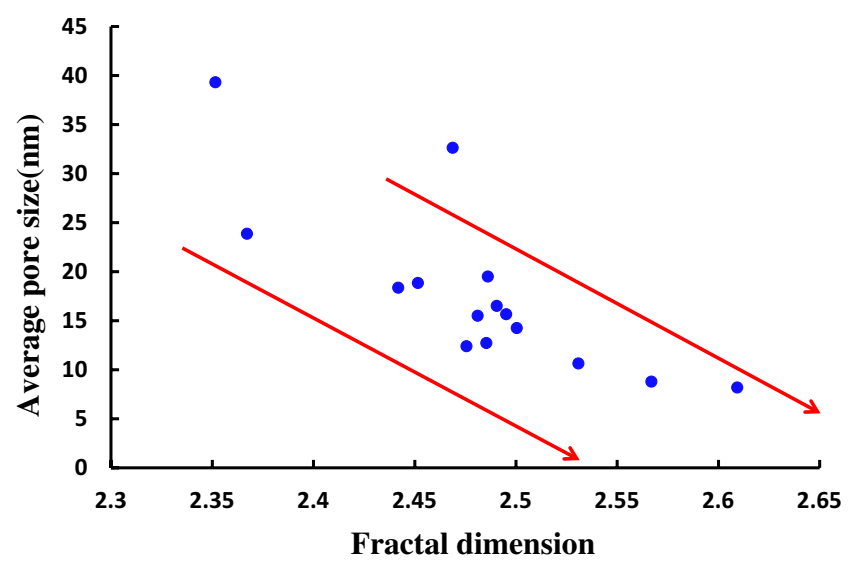

Fig. 10 The relations between fractal dimension and average pore size.

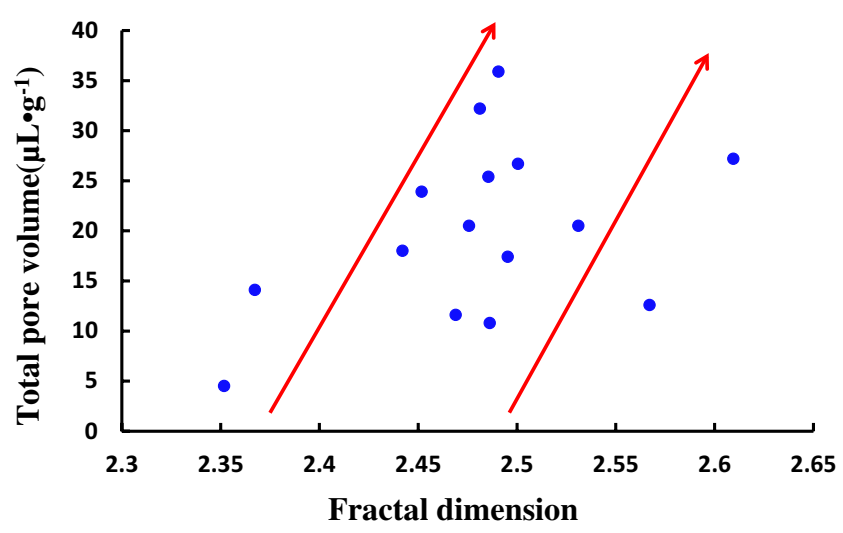

Fig. 11 Fractal dimension versus total pore volume.

\subsubsection{Analysis of the microscopic pores}

In this study, volcanic rock samples from the Haerjiawu Formation were investigated using FESEM, in order to verify whether the nanoscale porosity of the 
volcanic rocks of the Haerjiawu Formation in the Santanghu Basin is related to dissolution. Based on the results of the analysis (Fig. 12), the porosity of these basaltic reservoirs interbedded with carbonaceous mudstones is dominated by dissolved pores, their shape is irregular and their connectivity is poor. Selective mineral dissolution is interpreted as a widespread phenomenon. Some minerals are completely dissolved, while retaining the original crystal-shaped impression. Some minerals are not completely dissolved, this results in a honeycomb surface. The large numbers of etched pores of varying sizes increase the roughness of the pore surface.

With increasing depth, the maturity of the carbonaceous mudstone interbeds gradually increases, and the amount of organic acids generated also increases, this therefore provides sufficient fluid for the dissolution of the deep volcanic rocks. In other words, the dissolution effects of the organic acids increases with increasing depth, and this results in an increase in the fractal dimension.

\subsubsection{Analysis of the geological significance of these observations}

Through the above analysis, it can be seen that pore connectivity of the reservoirs is still poor, despite the presence of the organic acid dissolution in the Haerjiawu volcanic rocks, Santanghu Basin. This is due to the fact that the dissolution of tight reservoirs during reservoir diagenesis has two effects: on the one hand, dissolution enhances the reservoir's effective reservoir space, and the generated oil and gas can migrate to the dissolution holes in a short distance, forming effective hydrocarbon accumulations; on the other hand, dissolution also reduces reservoir seepage capacity. This is due to the fact that a large amount of feldspar is contained in the mineral composition of the volcanic reservoirs of the Haerjiawu Formation in the Santanghu Basin. As feldspar is an unstable mineral that is easily dissolved to produce kaolinite or quartz under the

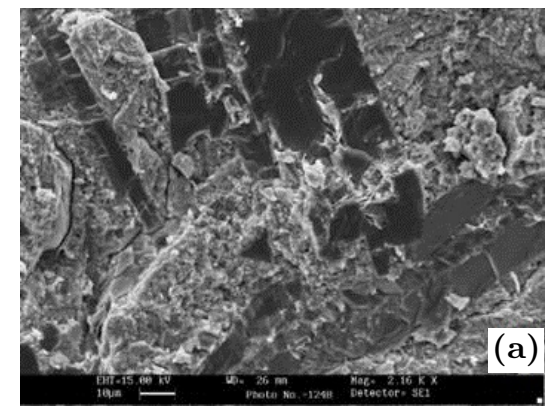

ND 201 well 3172.255m Brecciated Crushed Basalt

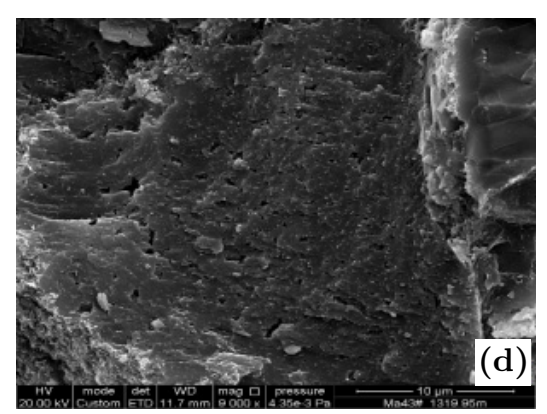

M43 well 1319.95m Organic Acid Dissolution - Basalt, see Corrosion Micropores

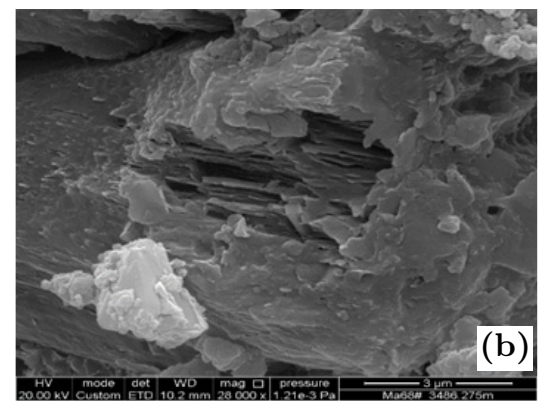

M68 well 3486.275mGray-green Fluorescent Basalt Dissolution Hole

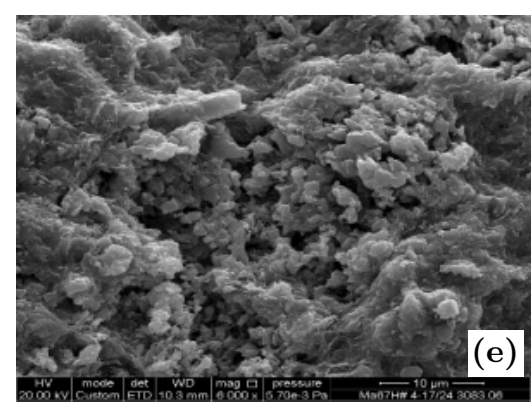

M67 well 3083.06m Organic Acid Dissolution - Basalt, see the Dissolution Hole

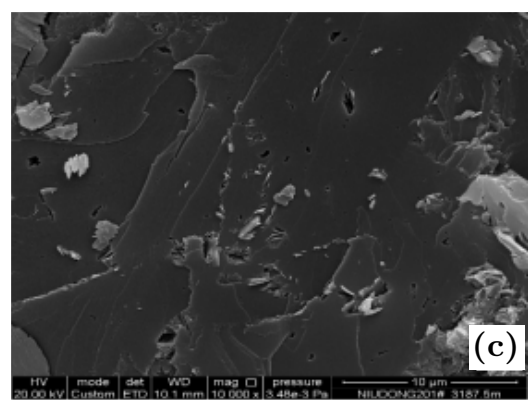

ND201 well 3187.5m Organic Acid Dissolution-Basalt

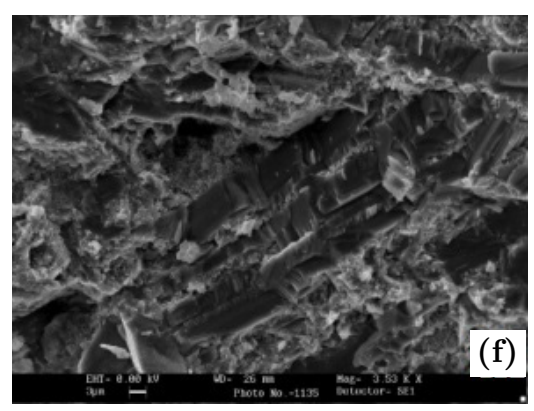

ND 201 well 31511.105m Dissolution and Clay Mineral Filling - Dark Gray Basalt

Fig. 12 Emission scanning electron micrograph of samples from the volcanic tight gas field in Haerjiawu Formation, Santanghu Basin. 


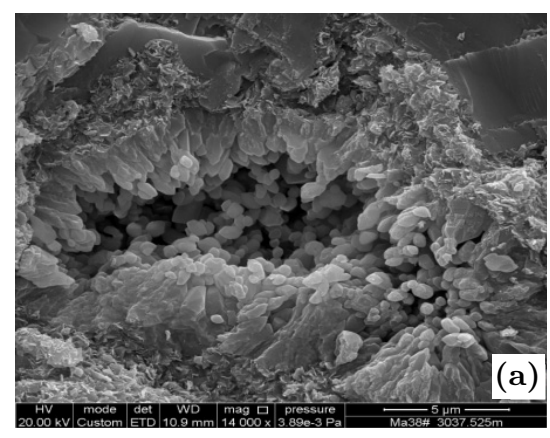

M38 well 3037.525m Corrosion hole Quartz Fill

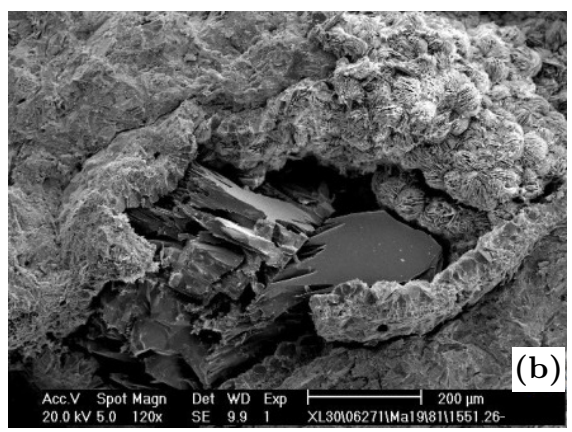

M19 well 1551.26m Chlorite Throat Sedimentation

Fig. 13 Emission maps of volcanic reservoirs in the Santanghu Basin.

action of organic acids (see Eqs. (4) and (5) $)^{48}$ :

$$
\begin{aligned}
& \mathrm{CaAl}_{2} \mathrm{Si}_{2} \mathrm{O}_{8}(\mathrm{An})+2 \mathrm{H}^{+}+\mathrm{H}_{2} \mathrm{O} \\
& =\mathrm{Al}_{2} \mathrm{Si}_{2} \mathrm{O}_{5}(\mathrm{OH})_{4}(\mathrm{KaO})+\mathrm{Ca}^{2+},
\end{aligned}
$$

Plagioclase $\longrightarrow$ Kaolinite,

$$
\begin{aligned}
& 2 \mathrm{KAlSi}_{3} \mathrm{O}_{8}(\mathrm{Kf})+2 \mathrm{H}^{+}+\mathrm{H}_{2} \mathrm{O} \\
& \quad=\mathrm{Al}_{2} \mathrm{Si}_{2} \mathrm{O}_{5}(\mathrm{OH})_{4}(\mathrm{KaO})+4 \mathrm{SiO}_{2}(\mathrm{Q})+2 \mathrm{~K}^{+},
\end{aligned}
$$

$K$-feldspar $\longrightarrow$ Kaolinite Quartz.

Feldspar dissolves newly formed kaolinite to generate new clay minerals such as chlorite (Eq. (6) ):

$$
\begin{aligned}
\mathrm{Al}_{2} \mathrm{Si}_{2} \mathrm{O}_{5}(\mathrm{OH})_{4}+\mathrm{H}_{2} \mathrm{O}+\mathrm{Fe}^{2+}+\mathrm{Mg}^{2+} \\
=\left(\mathrm{Fe}_{1.4} \mathrm{Mg}_{2.1} \mathrm{Al}_{2.5}\right)\left(\mathrm{Al}_{0.7} \mathrm{Si}_{3.3}\right) \\
\mathrm{O}_{10}(\mathrm{OH})_{8}+\mathrm{H}^{+},
\end{aligned}
$$

Kaolinite $\longrightarrow$ Chlorite.

The volcanic rocks of the Haerjiawu Formation in the Santanghu Basin are tight reservoirs with complex pore throats and a lack of effective channels for the outward discharge of new minerals. The newly formed quartz, chlorite and other minerals easily precipitate in the fine throats, clogging pores and throats, resulting in more complex pore connectivity while enhancing the micro-accumulation of tight oil and gas in the pores (Fig. 13).

\section{CONCLUSIONS}

(1) The volcanic rocks of the Haerjiawu Formation in the Santanghu Basin are characterized by nanoscale porosity. The pore morphology is dominated by "ink bottle"-shaped holes with wide mouths and narrow bodies, accompanied by a small number of "slit holes" with parallel plate-shaped structures. The volcanic reservoirs in the target layer are dominated by dissolution pores, and the pore surface roughness is relatively high with poor pore connectivity and obvious selective mineral erosion.

(2) The pore size distribution of the nanoscale pores spans a wide range, from $8.18 \mathrm{~nm}$ to $39.29 \mathrm{~nm}$. As depth increases, average pore diameter decreases gradually, the number of pores between $2 \mathrm{~nm}$ and $50 \mathrm{~nm}$ increases and therefore total pore volume increases. This is interpreted as indicating an increase in erosion volume and sample heterogeneity.

(3) As the depth increases, so does the fractal dimension. The larger the fractal dimension, the larger the BET-specific surface area and therefore the total pore volume. It is demonstrated that as the depth of the sample increases, the strength of the dissolution increases, resulting in a large number of pores with poor connectivity.

(4) Dissolution of the volcanic tight reservoirs in the target layer on the reservoir transformation is mainly reflected in two aspects: on the one hand, dissolution increases the total pore volume and provides effective reservoir space for tight oil and gas; on the other hand, dissolution occurs in tight reservoir systems. The newly formed minerals lack effective channels for discharge and are prone to reprecipitate in fine pores or throats, reducing reservoir permeability, but also enhancing reservoir micropreservation conditions.

\section{ACKNOWLEDGMENTS}

This study was financially supported by the National Natural Science Foundation of China (Nos. 41672125, 41330313, 41472105 and 41772131), Shandong Provincial Key Laboratory of Depositional Mineralization \& Sedimentary 
Mineral, Shandong University of Science and Technology (DMSM2017068); National Science and Technology Major Project (2016ZX05029002002, 2016ZX05034004-003), and the Fundamental Research Funds for the Central Universities (17CX05015B).

\section{REFERENCES}

1. S. J. Wang et al., New advance in resources evaluation of tight oil, Acta Petrol. Sin. 35 (2014) 10951105 .

2. R. G. Loucks et al., Morphology, genesis, and distribution of nanometer-scale pores in siliceous mudstones of the Mississippian barnett shale, J. Sediment Res. 79 (2015) 848-861.

3. R. M. Pollastro et al., Assessment of undiscovered technically recoverable oil and gas resources of the Bakken formation, Williston Basin, Montana and North Dakota, 2008, Ferroelectrics 360 (2008) 5762.

4. T. Liang et al., Influence factors of single well's productivity in the Bakken tight oil reservoir, Williston basin, Petrol. Explor. Dev. 40 (2013) 383388.

5. H. Bai et al., Hydrocarbon expulsion potential of source rocks and its influence on the distribution of lacustrine tight oil reservoir, Middle Permian Lucaogou Formation, Jimsar Sag, Junggar Basin, Northwest China, J. Petrol. Sci. Eng. 149 (2016) 740-755.

6. Q. L. Guo et al., Method for assessment of tight oil resources, China Petrol. Explor. 2 (2013) 68-76.

7. Q. L. Guo et al., Methodology, new software system and key technology for tight oil resources assessment, Nat. Gas Geosci. 27 (2016) 1566-1575.

8. T. Hu et al., Source rock characteristics of Permian Lucaogou Formation in the Jimusar Sag, Junggar Basin, northwest China, and its significance on tight oil source and occurrence, Geol. J. 52 (2016) 624645.

9. D. L. Lin et al., Review on gas flow and recovery in unconventional porous rocks, Adv. Geo-Energy Res. 1 (2017) 39-53.

10. W. D. Wang et al., A review of stimulated reservoir volume characterization for multiple fractured horizontal well in unconventional reservoirs, $A d v$. GeoEnergy Res. 1 (2017) 54-63.

11. Z. Qiu et al., Unconventional petroleum resources assessment: Progress and future prospects, Nat. Gas Geosci. 24 (2013) 238-246.

12. Z. Chen and K. G. Osadetz, An assessment of tight oil resource potential in Upper Cretaceous Cardium formation, Western Canada sedimentary basin, Petrol. Explor. Dev. 40 (2013) 344-353.
13. M. Y. Hou and G. F. Yang, The status and impact of tight oil in North America, Int. Petrol. Econ. 21 (2013) 11-16.

14. J. H. Du et al., Progress in China's tight oil exploration and challenges, China Petrol. Explor. 19 (2014) 1-9.

15. C. Z. Jia, Assessment criteria, main types, basic features and resource prospects of the tight oil in China, Acta Petrol. Sin. 33 (2012) 343-350.

16. S. H. Lin et al., Status quo of tight oil exploitation in the United States and its implication, Lithol. Res. 23 (2011) 25-27.

17. Z. Qiu et al., Exploration status, main geologic characteristics and their differences of tight oil between America and China, Lithol. Res. 27 (2015) 119-126.

18. H. Liang et al., Geological features and exploration potential of Permian Tiaohu formation tight oil, Santanghu Basin, NW China, Petrol. Explor. Dev. 41 (2014) 616-627.

19. W. B. Huang et al., Reservoir spaces in tight sandstones: Classification, fractal characters, and heterogeneity, J. Nat. Gas Sci. Eng. 46 (2017) 80-92.

20. Y. B. Zhou et al., Effect of adsorption-induced matrix deformation on coalbed methane transport analyzed using fractal theory, J. Nat. Gas Sci. Eng. 26 (2015) 840-846.

21. T. S. Xiao et al., Combining nuclear magnetic resonance and rate-controlled porosimetry to probe the pore-throat structure of tight sandstones, Petrol. Explor. Dev. 43 (2016) 1049-1059.

22. J. C. Cai et al., Fractal analysis of invasion depth of extraneous fluids in porous media, Chem. Eng. Sci. 65 (2010) 5178-5186.

23. J. C. Cai et al., Fractal characterization of dynamic fracture network extension in porous media, Fractals 25 (2017) 1750023.

24. J. N. Pan et al., Micro-pores and fractures of coals analysed by field emission scanning electron microscopy and fractal theory, Fuel 164 (2016) 277285.

25. J. B. W. Webber et al., An NMR study of porous rock and biochar containing organic material, Microporous Mesoporous Mater. 178 (2013) 9498.

26. X. Z. Wu et al., Structure evolution and petroleum accumulation of Santanghu basin, China J. Geol. 46 (2011) 808-825.

27. F. Yang et al., Pore structure of shales from high pressure mercury injection nitrogen adsorption method, Nat. Gas Geosci. 84 (2013) 450-455.

28. J. W. Liu et al., A new method for analysis of dual pore size distributions in shale using nitrogen adsorption measurements, Fuel 210 (2017) 446-454.

29. H. Q. Pang et al., Investigation of pore structure of a argillaceous rocks reservoir in the 5th member of Xujiahe Formation in Western Sichuan, using NAM, 
NMR and AIP-FESEM, Rock Min. Anal. 36 (2017) 66-74.

30. D. F. Zhao et al., Characteristics of macronanopores in anthracite coal based on mercury injection, nitrogen adsorption and FE-SEM, J. China Coal Soc. 42 (2017) 1517-1526.

31. J. T. Zheng et al., Characterization of nanopore morphology of shale and its effects on gas permeability, J. Nat. Gas Sci. Eng. 47 (2017) 83-90.

32. J. C. Cai et al., An analytical model for spontaneous imbibition in fractal porous media including gravity, Colloids Surf. A 414 (2012) 228-233.

33. K. Q. Liu et al., Nanoscale pore structure characterization of the Bakken shale in the USA, Fuel 209 (2017) $567-578$.

34. D. Z. Zhang, Characterization of microscopic pore structure of tight sandstone reservoirs through nitrogen adsorption experiment: Case study of Shahezi formation in Xujiaweizi fault depression, Songliao Basin, China, Nat. Gas Geosci. 28 (2017) 898908.

35. S. I. Pyun and C. K. Rhee, An investigation of fractal characteristics of mesoporous carbon electrodes with various pore structures, Electrochim. Acta $\mathbf{4 9}$ (2004) 4171-4180.

36. N. R. Khalili, M. Pan and G. Sandi, Determination of fractal dimensions of solid carbons from gas and liquid phase adsorption isotherms, Carbon 38 (2000) 573-588.

37. A. D. Budaeva and E. V. Zoltoev, Porous structure and sorption properties of nitrogen-containing activated carbon, Fuel 89 (2010) 2623-2627.

38. H. Liu et al., The configuration analysis of the adsorption isotherm of nitrogen in low temperature with the lignite char produced under fast pyrolysis, J. China Coal. Soc. 30 (2005) 507-510.

39. S. B. Chen et al., Structure characteristics and accumulation significance of nanopores in Longmaxi shale gas reservoir in the southern Sichuan Basin, $J$. China Coal. Soc. 37 (2012) 438-444.

40. W. Jiang et al., Study on fractal features of shale pore based on low temperature nitrogen absorption experiment, Coal. Sci. Technol. 44 (2016) 167-171.

41. B. B. Mandelbrot and J. A. Wheeler, The fractal geometry of nature, J. R. Stat. Soc. 4 (1983) 468.

42. Y. H. Chen, Y. Wang and X. M. Li, Application status and future of fractal in the research of surface and interface of material, Surf. Technol. 5 (2003) $8-11$.

43. J. L. P. Benoit and M. A. Bello, Fractal geometry and mercury porosimetry: Comparison and application of proposed models on building stones, Appl. Surf. Sci. 185 (2001) 99-107.

44. P. Pfeifer, M. Obert and M. W. Cole, Fractal BET and FHH theories of adsorption: A comparative study, Proc. R. Soc. Lond. 423 (1989) 169-188.

45. A. V. Neimark and K. K. Unger, Method of discrimination of surface fractality, J. Colloid Interf. Sci. 158 (1993) 412-419.

46. W. Wei et al., An electrical conductivity model for fractal porous media, Geophys. Res. Lett. 42 (2015) 4833-4840.

47. D. Avnir and M. Jaroniec, An isotherm equation for adsorption on fractal surfaces of heterogeneous porous materials, Langmuir 5 (1989) 1431-1433.

48. G. Q. Zhao et al., Feldspar corrosion and secondary pore formation in the upper paleozoic gas reservoir, Ordos Basin, Petrol. Explor. Dev. 32 (2005) 53-55. 